\title{
Ebstein anomaly associated with double-orifice tricuspid valve
}

\author{
Keiichi Itatani, MD, Kagami Miyaji, MD, PhD, Nobuyuki Inoue, MD, and Kuniyoshi Ohara, MD, PhD,
} Kanagawa, Japan

\section{CLINICAL SUMMARY}

A 1-year-old girl with Ebstein anomaly and atrial septal defect (ASD) was referred to us. She was born at 32 weeks' gestation and weighed $894 \mathrm{~g}$ at birth. She then underwent a video-assisted thoracoscopic interruption of a patent ductus arteriosus. Subsequently, cyanosis appeared and an

\footnotetext{
From the Department of Cardiovascular Surgery, Kitasato University School of Medicine, Sagamihara, Kanagawa, Japan.

Disclosures: None.

Received for publication June 19, 2009; revisions received Aug 16, 2009; accepted for publication Sept 8, 2009; available ahead of print Nov 12, 2009.

Address for reprints: Kagami Miyaji, MD, PhD, 1-15-1 Kitasato, Sagamihara, Kanagawa 224-8555, Japan (E-mail: Kagami111@aol.com).

J Thorac Cardiovasc Surg 2010;139:e131-3

$0022-5223 / \$ 36.00$

Copyright (C) 2010 by The American Association for Thoracic Surgery doi:10.1016/j.jtcvs.2009.09.017
}

echocardiogram demonstrated severe tricuspid valve regurgitation and a large ASD. The precise and repeated echocardiogram enabled us to diagnose Ebstein anomaly, even though the morphologic details of the tricuspid valve were not clear at that time. Echocardiography revealed that the downward displacement of the septal leaflet and tricuspid regurgitation were detected only through the four-chamber view and that, through other views, there seemed no anomaly in the septal leaflet, which later turned out to be an accessory leaflet at surgery (Figure 1, $A-C$ ). Cardiac catheterization at 1 year revealed that the pulmonary/systemic blood flow ratio was 0.71 , the pulmonary arterial resistance was $4.48 \mathrm{U} \cdot \mathrm{m}^{2}$, the arterial oxygen saturation was $80 \%$, and the end-systolic right ventricular volume was $164 \%$ of normal. The septal and posterior leaflets were displaced downward, and an atrialized right ventricle was



FIGURE 1. A, Preoperative echocardiogram (four-chamber view). The septal leaflet was displaced downward and tricuspid regurgitation was severe. B. Another view of the preoperative echocardiogram. The accessory leaflet seemed as if it were the septal leaflet without displacement. C and D, Schema of the double-orifice tricuspid valve. There was an accessory leaflet between the anterior and septal leaflets. Dotted lines explain the A and B views of echocardiogram. $R V$, Right ventricle. 

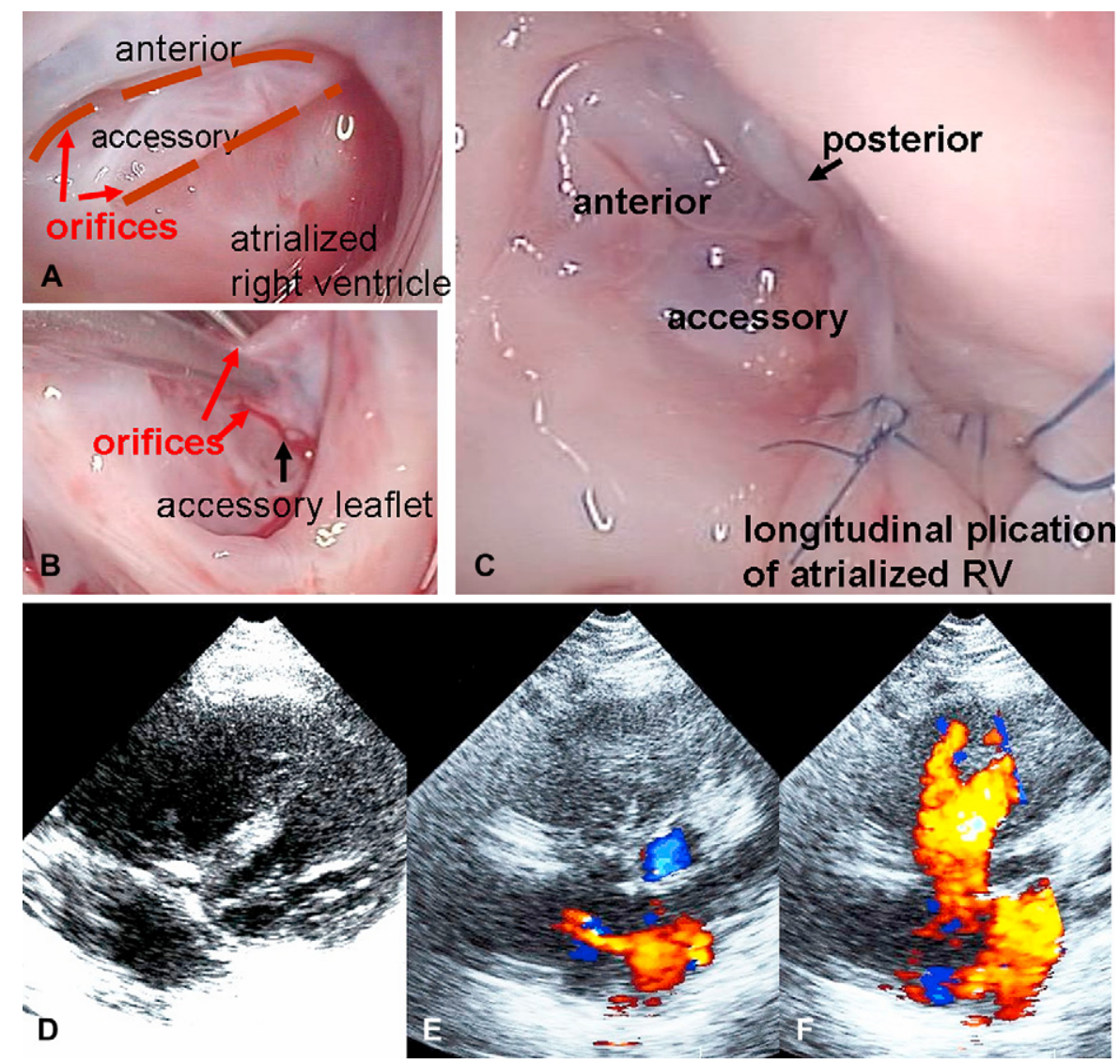

FIGURE 2. A and B, Operative findings of the tricuspid valve. There was an accessory leaflet between the anterior and septal leaflets. The valve had a double orifice and the cause of the regurgitation was the orifice between the accessory and posterior leaflets. C, Repaired tricuspid valve. The accessory valve was detached from the posterior papillary muscle and sutured to the natural tricuspid annulus level. D, E and F, Postoperative echocardiogram (four-chamber view) taken 6 months after the operation. Coaptation of the tricuspid valve was good (D) and there was only trivial regurgitation (E). No tricuspid stenosis was detected (F). $R V$, Right ventricle.

found above these leaflets. Therefore, the patient was referred for repair of the Ebstein anomaly.

With the patient supported by cardiopulmonary bypass with aortic and bicaval cannulation, cardiac arrest was achieved. The tricuspid valve was inspected through the right atriotomy. The anterior leaflet was of normal size, and the posterior and septal leaflets were displaced about $15 \mathrm{~mm}$ below the annular ring. There was another accessory leaflet between the anterior leaflet and hypoplastic septal leaflet (double-orifice tricuspid valve, Figure 2, $A$ and $B$ ). The posterior wall of the right ventricle above the septal and posterior leaflets was atrialized. The orifice on the septal leaflet side was small and caused the regurgitation, whereas the orifice on the anterior leaflet side was relatively large (14 mm).

The atrialized right ventricle was plicated longitudinally. The chordae tendineae of the accessory leaflet attached to the posterior papillary muscle were detached. The posterior edge of the accessory leaflet was then sutured to the natural tricuspid valve annulus creating a "new septal leaflet" using the accessory leaflet (Figure 2, $C$ ). The new annular diameter of the tricuspid valve became $14 \mathrm{~mm}$, which was about $89 \%$ of the normal annular size. The ASD was closed with a polytetrafluoloethylene patch with a 5-mm fenestration. Intraoperative transesophageal echocardiography demonstrated no tricuspid regurgitation. The postoperative course was uneventful and the patient was discharged 10 days postoperatively. The echocardiogram taken 6 months after the operation revealed good coaptation of the tricuspid valve (Figure 2,D) with trivial regurgitation (Figure 2,E) and no tricuspid stenosis (Figure 2, F).

\section{DISCUSSION}

Ebstein anomaly associated with double-orifice tricuspid valve is extremely uncommon, with only two case reports in the literature to date. ${ }^{1,2}$ Sánchez Carlos, Rábago, and Sokolowski ${ }^{1}$ proposed a classification of double orifice in the tricuspid valve: A, commissural type; B, central type; and $\mathrm{C}$, hole type. They reported 2 cases of Ebstein anomaly with double orifice in the tricuspid valve. ${ }^{1}$ One was the central type, in which separations of the orifices were complete and each orifice had an independent set of chordae and 
papillary muscles. Another was the hole type, in which there was a simple large hole in a cusp. Miyamura and associates ${ }^{2}$ reported a case of central-type anomaly, in which the anterior leaflet was divided completely with a well-developed papillary muscle and chordae tendineae. The present case was similar to the case of Miyamura and associates ${ }^{2}$ : the tricuspid valve had a completely independent accessory leaflet with well-developed apparatus structures.

Procedures for correction of the Ebstein anomaly that restore the tricuspid valve to near normal anatomic and physiologic function have been reported, ${ }^{3-5}$ other than monocuspid valve reconstruction using an enlarged anterior leaflet. Valve reparability is reported to depend on the valve leaflet location and morphologic features. ${ }^{1}$ Da Silva and colleagues ${ }^{4}$ reported a surgical technique called "cone reconstruction," in which the anterior and posterior tricuspid valve leaflets mobilized from the right ventricle were rotated clockwise, creating a cone, the base of which was sutured to the true tricuspid valve annulus level, and its free edge was sutured to the septal border of the anterior leaflet. Wu and associates ${ }^{5}$ reported anatomic repair using posterior and sep- tal leaflets, a "new leaflet" being made from the posterior and septal leaflets or a piece of fresh autologous pericardium depending on the size of the septal and posterior leaflets. Our surgical technique was the modification of the concept of creating "new septal leaflet" repairs using the accessory leaflet. To our knowledge this is the first case reported in the literature of a patient with Ebstein anomaly associated with double orifice of the tricuspid valve who underwent successful surgical repair.

\section{References}

1. Sánchez Carlos A, Rábago P, Sokolowski M. Duplication of the tricuspid valve. $\mathrm{Br}$ Heart J. 1967;29:943-6.

2. Miyamura H, Matsukawa T, Maruyama Y, Nakazawa S, Eguchi S. Duplication of the tricuspid valve with Ebstein anomaly. Jpn Circ J. 1984;48:336-8.

3. Brown ML, Dearani JA, Danielson GK, Cetta F, Connolly HM, Warnes CA, et al Mayo Clinic Congenital Heart Center. The outcomes of operations for 539 patients with Ebstein anomaly. J Thorac Cardiovasc Surg. 2008;135:1120-36.

4. da Silva JP, Baumgratz JF, da Fonseca L, Franchi SM, Lopes LM, Tavares GMP, et al. The cone reconstruction of the tricuspid valve in Ebstein's anomaly. The operation: early and midterm results. J Thorac Cardiovasc Surg. 2007;133:215-23.

5. Wu Q, Huang Z, Pan G, Wang L, Li L, Xue H. Early and midterm results in anatomic repair of Ebstein anomaly. J Thorac Cardiovasc Surg. 2007;134: $1438-42$.

\title{
Right ventricular approach for securing the aortic homograft to the interventricular septum in bacterial endocarditis
}

\author{
Morteza Tavakkoli Hosseini, MD, Antonios Kourliouros, MRCS, and Mazin Sarsam, FRCS, London, \\ United Kingdom
}

We present here a case of aortic homograft implantation for aortic root abscess with involvement of the interventricular septum. Because of the extensive involvement of the septum, the conventional approach for securing the homograft to the interventricular septum failed, and subsequently the homograft was fixed to the septum by direct approach through the right ventricle.

\section{CLINICAL SUMMARY}

A 27-year-old man with methicillin-resistant Staphylococcus aureus septicemia resulting from dialysis line infec-

\footnotetext{
From the Department of Cardiothoracic Surgery, St Georges Hospital, London, United Kingdom.

Disclosures: None.

Received for publication May 22, 2009; accepted for publication Sept 8, 2009; available ahead of print Nov 12, 2009.

Address for reprints: Mazin Sarsam, FRCS, Department of Cardiothoracic Surgery, St Georges Hospital, BlackShaw Rd, London SW17 0QT, United Kingdom (E-mail: mazin.sarsam@stgeorges.nhs.uk).

J Thorac Cardiovasc Surg 2010;139:e133-4

$0022-5223 / \$ 36.00$

Copyright (c) 2010 by The American Association for Thoracic Surgery

doi:10.1016/j.jtcvs.2009.09.020
}

tion had the symptoms of pulmonary edema and shortness of breath. Echocardiography showed $4+$ aortic regurgitation with complete destruction of the aortic valve, aortic root abscess extending to the interventricular septum along the right coronary sinus of Valsalva, mild mitral regurgitation with clear mitral valve leaflets, an area of localized infection on the tricuspid valve between the commissure of the septal and posterior leaflets, and a $4 \times 4-\mathrm{cm}$ mass in the right atrium near the inferior vena cava. The patient's medical history included sickle cell trait, ulcerative colitis, hemolytic uremic syndrome, and resultant renal failure.

The patient was taken to the operating room for emergency aortic root replacement and removal of the right atrial mass. After median sternotomy, aortobicaval cardiopulmonary bypass was established. No significant abnormalities were noticed at the surface of the heart. The right atrium was opened, and the friable mass along the inferior vena cava was removed. An area of localized infection was found on the tricuspid valve between the posterior and septal leaflets. It was débrided and washed with vancomycin with preservation of the tricuspid valve. The ascending aorta was 